OPEN ACCESS

Edited by:

David Honys,

Institute of Experimental Botany,

Czech Academy of Sciences, Czechia

Reviewed by:

Jorge Muschietti,

CONICET Instituto de Investigaciones en Ingeniería Genética y Biología Molecular "Dr. Héctor N. Torres"

(INGEBI), Argentina

Hua Jiang,

Leibniz Institute of Plant Genetics and Crop Plant Research (IPK),

Germany

*Correspondence:

Lian Zhou

zhoulianjojo@swu.edu.cn

John E. Fowler

john.fowler@oregonstate.edu

Specialty section:

This article was submitted to Plant Development and EvoDevo,

a section of the journal

Frontiers in Plant Science

Received: 30 November 2020 Accepted: 08 February 2021

Published: 25 February 2021

Citation:

Zhou L, Vejlupkova Z, Warman C and Fowler JE (2021) A Maize Male Gametophyte-Specific Gene Encodes

ZmLARP6C1, a Potential

RNA-Binding Protein Required for Competitive Pollen Tube Growth.

Front. Plant Sci. 12:635244.

doi: $10.3389 / \mathrm{fp} / \mathrm{s} .2021 .635244$

\section{A Maize Male Gametophyte-Specific Gene Encodes ZmLARP6c1, a Potential RNA-Binding Protein Required for Competitive Pollen Tube Growth}

\author{
Lian Zhou'*, Zuzana Vejlupkova², Cedar Warman² and John E. Fowler²* \\ ${ }^{1}$ Maize Research Institute, College of Agronomy and Biotechnology, Southwest University, Chongqing, China, ${ }^{2}$ Department \\ of Botany and Plant Pathology, Oregon State University, Corvallis, OR, United States
}

Members of the La-related protein family (LARPS) contain a conserved La module, which has been associated with RNA-binding activity. Expression of the maize gene GRMZM2G323499/Zm00001d018613, a member of the LARP family, is highly specific to pollen, based on both transcriptomic and proteomic assays. This suggests a pollenspecific RNA regulatory function for the protein, designated ZmLARP6c1 based on sequence similarity to the LARP6 subfamily in Arabidopsis. To test this hypothesis, a Ds-GFP transposable element insertion in the ZmLarp6c1 gene (tdsgR82C05) was obtained from the Dooner/Du mutant collection. Sequencing confirmed that the DsGFP insertion is in an exon, and thus likely interferes with ZmLARP6c1 function. Tracking inheritance of the insertion via its endosperm-expressed GFP indicated that the mutation was associated with reduced transmission from a heterozygous plant when crossed as a male (ranging from 0.5 to $26.5 \%$ transmission), but not as a female. Furthermore, this transmission defect was significantly alleviated when less pollen was applied to the silk, reducing competition between mutant and wild-type pollen. Pollen grain diameter measurements and nuclei counts showed no significant differences between wild-type and mutant pollen. However, in vitro, mutant pollen tubes were significantly shorter than those from sibling wild-type plants, and also displayed altered germination dynamics. These results are consistent with the idea that ZmLARP6c1 provides an important regulatory function during the highly competitive progamic phase of male gametophyte development following arrival of the pollen grain on the silk. The conditional, competitive nature of the Zmlarp6c1::Ds male sterility phenotype (i.e., reduced ability to produce progeny seed) points toward new possibilities for genetic control of parentage in crop production.

Keywords: maize, ZmLARP6c1, pollen competition, pollen germination, pollen tube growth, RNA-binding protein 


\section{INTRODUCTION}

The life cycle of plants alternates between haploid and diploid phases, called the gametophyte and sporophyte, respectively (Walbot and Evans, 2003). Flowering plants have male and female gametophytes, both of which consist of multiple cells and require regulation of gene expression for their function. For the male gametophyte, pollen grain development initiates inside the anther post-meiosis, with the unicellular microspore. In maize, the mature pollen grain consists of a vegetative cell and two sperm cells after two mitoses during its development. When the pollen grain arrives at the maize silk, progamic development commences, as the pollen tube germinates and its growth is directed to the embryo sac for fertilization (Cheung et al., 1995; Hulskamp et al., 1995; Johnson et al., 2019). Proper elongation of the pollen tube is essential for fertilization (Dresselhaus et al., 2016; Hafidh et al., 2016).

Analysis of the male gametophyte transcriptome in multiple plant species, including maize, indicates that there are numerous genes specifically expressed in the male gametophyte, apparently distinct from any expression or function in the sporophyte (Honys and Twell, 2004; Pina et al., 2005; Chettoor et al., 2014; Rutley and Twell, 2015; Warman et al., 2020). Relatively few of these genes have been characterized in vivo with respect to their effect on reproductive success, i.e., their contribution to successful pollen tube growth, sperm cell delivery, fertilization and seed set, particularly in monocots (Procissi et al., 2001; Lalanne and Twell, 2002; Kim et al., 2019; Lopes et al., 2019). Notably, mutations in genes active in the male haploid gametophyte are associated with reduced transmission through the male, as loss of important genetic functions can impair the ability to compete with wild-type pollen tubes, therefore reduce reproductive success, i.e., fitness (Arthur et al., 2003; Warman et al., 2020). This reduced transmission can make the generation of mutant homozygotes difficult, and it can also conceivably reduce the recovery or maintenance of such mutations in a population. Notably, although a number of cell biological regulators active during progamic development have been characterized by mutation (Chang et al., 2013; Kaya et al., 2014; Huang et al., 2017), few direct regulators of gene expression enabling pollen tube growth have been genetically defined (Lago et al., 2005; Adamczyk and Fernandez, 2009; Reňák et al., 2012).

In higher plants, post-transcriptional regulation is essential for proper gene expression during floral development and hormone signaling (Fedoroff, 2002; Kramer et al., 2018; Cho et al., 2019; Prall et al., 2019). RNA-binding proteins are associated with post-transcriptional regulation, including pre-mRNA processing, transport, localization, translation and stability of mRNAs (Dreyfuss et al., 2002; Dedow and Bailey-Serres, 2019). In particular, RNA-binding proteins harboring an RNA recognition motif (RRM) at the $\mathrm{N}$-terminus and a glycine-rich region at the $\mathrm{C}$-terminus are thought to play crucial roles in plant growth and stress responses (Ciuzan et al., 2015; Koster et al., 2017).

The La-related proteins (LARP) are a large and diverse superfamily, each member harboring the La module, comprised of two conserved and closely juxtaposed domains that are thought to promote RNA binding: the La motif followed by an RRM motif (Koster et al., 2017; Maraia et al., 2017). The superfamily is further divided into five families: LARP1, LARP3 (encompassing the original La protein), LARP4, LARP6, and LARP7, based on structural features and evolutionary history (Bousquet-Antonelli and Deragon, 2009; Bayfield et al., 2010; Deragon, 2020). Several members of these families have been proven to be RNA-binding proteins. The La protein binds to RNA polymerase III (RNAP III) transcripts at the singlestranded UUU-3' OH (Wolin and Cedervall, 2002). LARP7 family members most closely resemble LARP3 but function with a single RNAP III nuclear transcript, 7SK, or telomerase RNA (Krueger et al., 2008; Eichhorn et al., 2016, 2018; Mennie et al., 2018). In animal cells, LARP1 and LARP4 bind to the $5^{\prime}$ and $3^{\prime}$ untranslated regions of mRNAs to regulate translation and degradation (Aoki et al., 2013; Merret et al., 2013b; Lahr et al., 2015). In plants, the roles of the LARP superfamily are only beginning to be characterized. For example, in Arabidopsis, the AtLal gene, a true La ortholog in the LARP3 family, is required for completion of embryogenesis, perhaps in part due to its role in promoting translation of the WUSCHEL (WUS) transcription factor, which is required for stem cell homeostasis. At the molecular level, AtLal appears to promote translation via interaction with the $5^{\prime} \mathrm{UTR}$ of the WUS mRNA (Fleurdepine et al., 2007; Cui et al., 2015). Members of the Arabidopsis LARP1 family have been linked to both leaf senescence and heat-induced mRNA decay (Zhang et al., 2012; Merret et al., 2013a). Most recently, LARP1 has been shown to regulate the translation of the subset of Arabidopsis transcripts bearing the $5^{\prime}$-terminal oligopyrimidine stretch (TOP) motif, as a key component of the target of rapamycin (TOR) pathway regulating cellular metabolism (Scarpin et al., 2020).

In contrast, there is no analogous cellular or organismal function yet identified for the LARP6 family. Only one endogenous RNA ligand has been identified: in mammals, LARP6 binds to a secondary structure element in the 5'UTR of type I collagen mRNAs (Cai et al., 2010). The LARP6 interdomain linker between the La motif and the RRM plays a critical role in this RNA binding activity (Martino et al., 2015). Intriguingly, certain members of the plant LARP6 family interact with the major plant poly(A)-binding protein (PAB2), and also show differential RNA-binding activity in vitro (Merret et al., 2013b).

Bioinformatics analyses (Merret et al., 2013b) showed that, in the maize genome, there are six genes encoding LARP6 family proteins (ZmLARP6a, ZmLARP6b1-b3, and ZmLARP6c1-c2). Here, we report that one of these genes (GRMZM2G323499/Zm00001d018613), which encodes ZmLARP6c1, is specifically and highly expressed in mature pollen. To begin defining the function of this gene, a Ds-GFP transposable element insertion (Li et al., 2013) in its coding sequence was obtained and confirmed. Characterization of this mutation and its phenotypes points toward an important malespecific function for ZmLARP6c1 in the haploid gametophyte during the highly competitive phase of pollen tube germination and growth following pollination. 


\section{MATERIALS AND METHODS}

\section{Plant Materials, Growth Conditions}

The Ds-GFP allele used in this study ( $t d s g R 82 C 05)$ was requested from the Maize Genetics Cooperation Stock Center based on its insertion location in the coding sequence of the larp $6 c 1$ gene $^{1}$. The mutation was backcrossed to a $c 1$ homozygous, predominantly W22 inbred line at least twice to insure heterozygosity and the presence of a single $D s$ GFP locus before use in the experiments described. Primers used to PCR-genotype mutant and wild-type alleles in plants from segregating families are listed in Supplementary Table 1. Genetic studies were carried out using standard procedures at the OSU Botany \& Plant Pathology Farm in Corvallis, OR, United States.

\section{Sequence Alignment and Phylogenetic Analysis}

The full-length sequences of ZmLARP6 and AtLARP6 family proteins were obtained from MaizeGDB ${ }^{2}$ and $\mathrm{TAIR}^{3}$. Multiple amino acid sequence alignment was conducted using MegAlign Software. Phylogenetic analysis was conducted using MEGA6 by neighbor-joining method (Tamura et al., 2013).

\section{RNA Extraction}

Plants for RNA were grown in summer field conditions in Corvallis, OR, United States. Fresh mature pollen was collected upon shedding between 11:00 am and 12:00 pm. Fifty milligrams pollen of each plant was quickly harvested, frozen in liquid nitrogen and stored at $-80^{\circ} \mathrm{C}$. Total RNA was isolated from mature pollen using Trizol Reagent (Thermo Fisher scientific, Cat no. 15569026$)$ with added PEG (20,000 MW) to $2 \%$ (Tattersall et al., 2005) and quantified via Nanodrop (ND-1000).

\section{Real-Time qRT-PCR}

First-strand cDNAs were synthesized from total RNA using SuperScript III First-strand synthesis system for RT-PCR kit (Invitrogen). Real-time qRT-PCR was performed using SYBR Premix EX TaqTM II (TAKARA) on a CFX96 Real-Time system (Bio-Rad), according to the manufacturer's instructions. The amplification program was performed at $95^{\circ} \mathrm{C}$ for $5 \mathrm{~s}, 60^{\circ} \mathrm{C}$ for $30 \mathrm{~s}$, and $72^{\circ} \mathrm{C}$ for $30 \mathrm{~s}$. Triplicate quantitative assays were performed on each cDNA sample. The relative expression was calculated using the formula $2^{-\Delta(\Delta \mathrm{cp})}$. The housekeeping gene ZmUbiquitin1 was used as an internal control. All primers used for real-time qRT-PCR are listed in Supplementary Table 1.

\section{In vitro Pollen Germination}

Plants for pollen germination experiments were grown in summer field conditions in Corvallis, OR, United States. Pollen was germinated in pollen germination medium (PGM - 10\% sucrose, $0.0005 \% \mathrm{H}_{3} \mathrm{BO}_{3}, 10 \mathrm{mM} \mathrm{CaCl}, 0.05 \mathrm{mM} \mathrm{KH}_{2} \mathrm{PO}_{4}, 6 \%$

\footnotetext{
${ }^{1}$ acdsinsertions.org
}

${ }^{2}$ https://maizegdb.org

${ }^{3}$ http://www.arabidopsis.org/
PEG 4000) (Schreiber and Dresselhaus, 2003) and imaged at 15 or $30 \mathrm{~min}$ after exposure to media. Germinated, ungerminated, and ruptured pollen were quantified from digital images using the FIJI distribution of ImageJ (Schindelin et al., 2012), with a minimum of 125 grains categorized for each datapoint. Pollen tube lengths were measured from homozygous larp6c1::Ds-GFP mutants and closely related wild-type comparator plants. Four replicates were measured with FIJI, with three homozygous mutants and three wild type plants used per replicate, and a minimum of 50 pollen tubes measured for each pollen collection.

\section{Statistical Analysis}

Statistical significance was determined using $t$-test or $1 \mathrm{~m}$ functions either in SAS (SAS Institute Inc. ${ }^{4}$ ) or with $\mathrm{R}$. Analysis of the categorical response in pollen germination (i.e., the proportion of germinated, ruptured, and ungerminated pollen grains) via logistic regression used the mblogit function (Baseline-Category Logit Models for Categorical and Multinomial Responses) of the mclogit package in R. The categorical dataset was modeled using Genotype + Timepoint + Replicate as factors, with dispersion estimated using the "Afroz" default. $R$ code and the original dataset are available upon request.

\section{Counting of Fluorescent Kernels}

Maize ears were scanned using a custom-built scanner and image projection pipeline (Warman et al., 2020, 2021). Green fluorescent (GFP) kernels and non-GFP kernels were counted using the digital image projections and the 'Cell Counter' plugin of the FIJI distribution of ImageJ.

\section{DyeCycle Green Pollen Staining}

Fresh pollen was collected from each plant, immediately fixed in ethanol: acetic acid (3:1 ratio) solution, and later rehydrated through an ethanol series for size measurements and staining. To visualize nuclei, fixed pollen grains were stained with DyeCycle Green (Thermo Fisher Scientific, Cat no. V35004) at a final concentration of $1 \mu \mathrm{M}$ in water, incubated in dark for $30 \mathrm{~min}$ and washed with sterile water. Stained pollen was then imaged on a Zeiss Axiovert S100 microscope equipped with HBO 50 Illuminator and Chroma \#41017 filter set (470/40 excitation, 495 long-pass dichroic, 525/50 emission) using Qimaging (Retiga ExI) camera.

\section{RESULTS}

\section{ZmLarp6c1 Encodes a Pollen-Specific Member of the LARP6 Family}

Members of the La-related protein family (LARPs) contain a conserved La motif (LAM) and an RNA recognition motif (RRM), which has been associated with RNA-binding activity. GRMZM2G323499/Zm00001d018613 is a member of the LARP family, and is predicted to encode a 505 amino

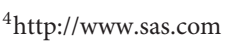


acid protein that harbors conserved La and RRM-like motifs (RRM-L) (Figure 1A). The presence of a conserved glycinerich C-terminal domain (the LSA: LAM and S1 associated motif) in six members of the maize LARP family is diagnostic for placing them in the LARP6 subgroup (Figure 1B). Consistent with earlier analyses, all but one of these also harbors the PABP-interacting motif 2 (PAM2) (Figure 1B), which may mediate binding to Poly(A)-Binding Protein (PABP) (Merret et al., 2013b). A phylogenetic tree was constructed based on the amino acid sequence alignment of LARP6 subgroups of maize and Arabidopsis. Phylogenetic analysis confirms that ZmLARP6c1 has a high degree of sequence similarity with other ZmLARP6s and that the evolutionarily closest Arabidopsis protein is AtLARP6c (Figure 1C). The closest LARP in maize, designated ZmLARP6c2, is encoded by GRMZM2G411041/Zm00001d032397 on chromosome 1, which is non-syntenic with ZmLarp6c1 near telomere of the chromosome 7S.

Expression of $Z m L a r p 6 c 1$ is highly specific to pollen, based on both transcriptomic and proteomic datasets (Supplementary Figure 1; Walley et al., 2016; Warman et al., 2020). To assess directly expression of all genes encoding members of the LARP6 family in maize pollen, total RNA was isolated from mature pollen collected from inbred line B73. Real-time qRT-PCR results showed that $Z m L a r p 6 c 1$ had the highest transcriptional abundance of all six ZmLarp6 family members in mature pollen
(Figure 1D). Together, these data suggest a pollen-specific RNA regulatory function for $\mathrm{Zm} \mathrm{LARP6c1.}$

\section{A ZmLarp6c1 Mutation Is Associated With Reduced Transmission When Crossed as a Male}

To investigate the function of $Z m L A R P 6 c 1$ during pollen development, a line carrying a $D s-G F P$ transposable element insertion in ZmLARP6c1 (Zmlarp6c1::Ds-GFP) was obtained from the Dooner/Du population (Li et al., 2013). Sequencing confirmed that the tdsgR82C05 insertion is in the fifth exon (Figure 2A) in the RRM-L domain coding region, and thus likely interferes with $Z m L A R P 6 c 1$ function. PCR genotyping primers were designed to confirm the co-segregation with the GFP marker, and identify the genotype (Figure 2B).

Neither heterozygous nor homozygous Zmlarp6c1::Ds-GFP plants showed any obvious differences in vegetative and floral development. As an initial assessment of effects on gametophytic development and function, Zmlarp6c1::Ds-GFP heterozygous mutant plants were reciprocally crossed with wild-type plants in the field. Inheritance of the insertion was tracked via its endosperm-expressed GFP, with the mutant and wildtype kernels quantified via annotation of $360^{\circ}$ ear projections (Figure 3). When crossed through the male, GFP transmission ranged from 0.5 to $26.5 \%$, showing significantly reduced
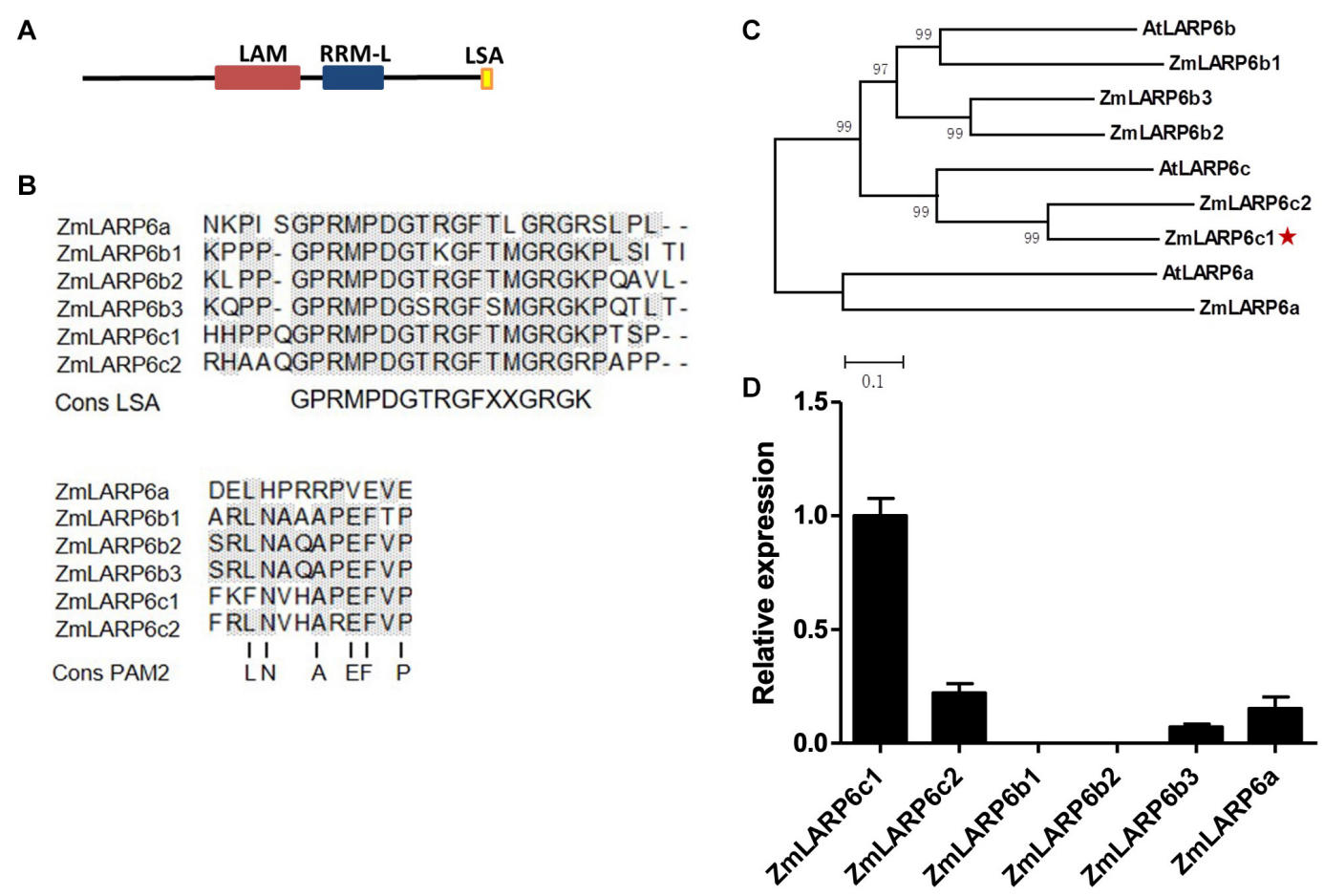

FIGURE 1 | Bioinformatic analysis and expression profiling of the maize LARP6 family members points toward a role for $Z m L a r p 6 c 1$ in maize pollen. (A) Predicted conserved domain architecture of ZmLARP6c1. (B) Alignments of maize LARP6 amino acid sequences alongside consensus sequences for the LSA motif and the PAM2 motif. Gray shade, matched residues. (C) Phylogenetic tree, using the entire amino acid alignment and the distance method. The bar indicates a mean distance of 0.1 changes per amino acid residue. (D) Relative transcript levels of ZmLARP6 genes in mature pollen of maize. Total RNA was extracted from mature pollen for qRT-PCR. All data are means of three biological replicates with error bars indicating SD. 


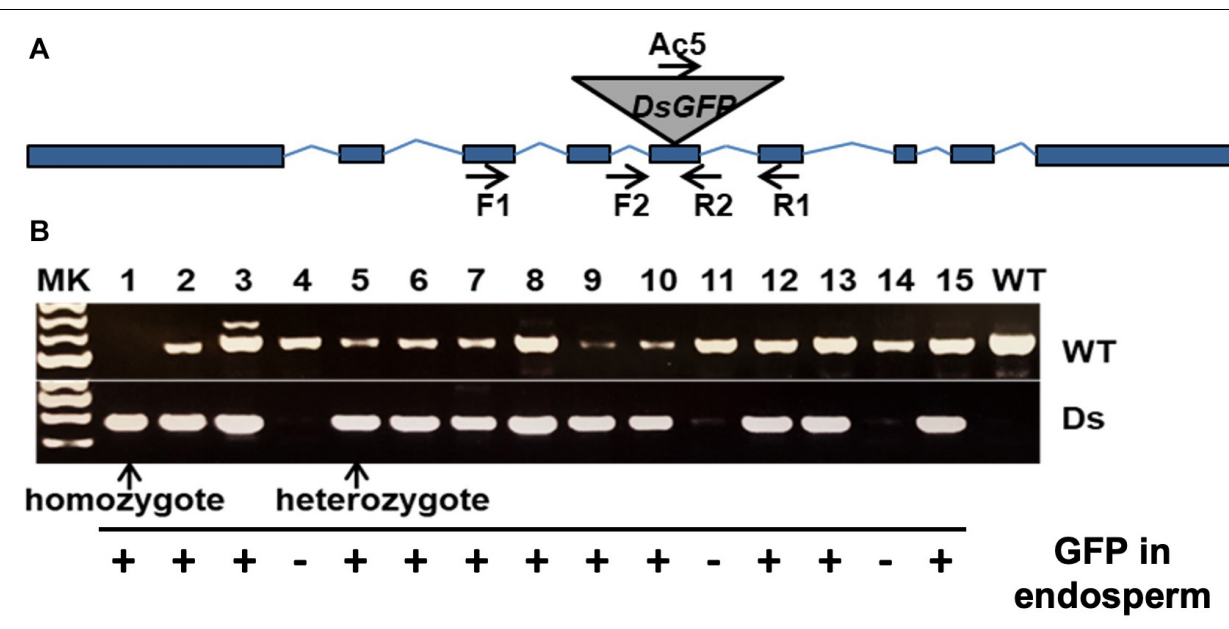

FIGURE 2 | A Ds-GFP transposable element insertion line provides a tool to investigate Zmlarp6c1 function. (A) Sequencing confirmed that the insertion was in the 5th exon; thus, the mutation, likely a knockout, could be easily tracked genetically by observing GFP fluorescence in the endosperm. (B) PCR genotyping of progeny (using primers F1, R1, and Ac5) from a self-pollinated heterozygote confirms co-segregation of the insertion with the GFP marker, and helps clarify genotype (homozygote vs. heterozygote).

transmission in every outcross in two field seasons $\left(\chi^{2}\right.$ test, $p$-values $<10^{-6}$ ), averaging $12.4 \%$ transmission across nine ears (Table 1). In contrast, female GFP transmission ranged from 47.2 to $56.7 \%$, averaging $51.4 \%$, with only a single cross significantly different from expected Mendelian inheritance (56.7\%, $p=0.008$ ) (Table 1). Self-crosses of heterozygous plants average a GFP transmission rate of $53.7 \%$, consistent with the expectation based on the male and female rates observed above (Supplementary Table 2). Notably, pollen from plants homozygous for Zmlarp6c1::Ds-GFP generated full ears when used in hand pollinations onto wild-type females, with seed set similar to that generated by comparable pollinations with wild-type homozygotes (Figures 3C,D). No significant difference was observed between the total number of seeds from mutant homozygotes vs. from wild-type homozygotes ( $p=0.43, t$-test).

To create derivative excision alleles to confirm that the insertion is causal for the male-specific transmission defect, Zmlarp6c1::Ds-GFP was crossed into an Ac-im active line (Conrad and Brutnell, 2005). Progeny were screened by PCR for excision, and 6 putative revertant alleles were identified. Two of these alleles were heritable and confirmed by sequencing (Figures 4A,B). As expected, there was a 8 bp duplication in the original Zmlarp6c1::Ds-GFP insertion allele compared to wildtype. Ds excision generated distinct nucleotide footprints in the two derivatives, with one footprint (dX549B2) adding six base pairs relative to the wild-type sequence and the other ( $d X 550 A 8)$ adding eight base pairs (Figure 4B). Given an insertion in the coding region, the eight-bp insertion would be predicted to generate a frameshift, and thus a likely non-functional LARP6c1 protein, whereas the six-bp footprint would insert two amino acids but retain the frame (Supplementary Figure 2), and thus potentially restore protein function. To test for altered functionality associated with these variant sequences, plants heterozygous for each of the two alleles were outcrossed as males with a heavy pollen load, and transmission was assessed via
PCR genotyping. As expected, the 8-bp footprint $d X 550 A 8$ allele retained a strongly reduced transmission rate ( $12.5 \%$, Figure $4 \mathrm{C})$. However, the 6-bp footprint $d X 549 B 2$ allele recovered a wildtype transmission rate $(54.2 \%$, Figure $4 D)$, indicating reversion of gene function. These data confirm that the interruption of the Zmlarp $6 c 1$ coding sequence by the original $t d s g R 82 C 05$ insertion was causal for the transmission defect, rather than an unknown, linked mutation.

\section{ZmLARP6c1 Contributes to Pollen Competitive Ability in vivo and to Robust Pollen Tube Growth in vitro}

Notable in the transmission tests was the observation that the male transmission rate was associated with high variance ( standard deviation $=9.6 \%$ ), relative to female transmission (standard deviation $=3.1 \%$ ). This raised the possibility that Zmlarp6c1::Ds pollen is particularly sensitive to an environmental factor that was variable across these ears. One such factor that can be easily tested is the level of competition i.e., the number of wild-type pollen grains competing with mutant pollen grains on each silk. A defect that is only expressed in competition with wild-type pollen would also explain how pollen from homozygous mutant plants can generate good seed set in hand pollinations (Figure $3 \mathrm{C}$ ). In four independent experiments, a single pollen collection from a mutant heterozygote was used to heavily pollinate silks of one ear (HVY), and to sparsely pollinate three other ears with limiting pollen (SPS) to reduce competition. In three of the four experiments, sparse pollination significantly relieved the GFP transmission defect, relative to the comparator heavy pollination, with transmission rates from 37.7 to $53.3 \%$ (Table 2). Because these experiments are inherently imprecise, we sought to find a measure to assess pollen load for each pollination. The total number of seeds per ear provides such an assessment, 

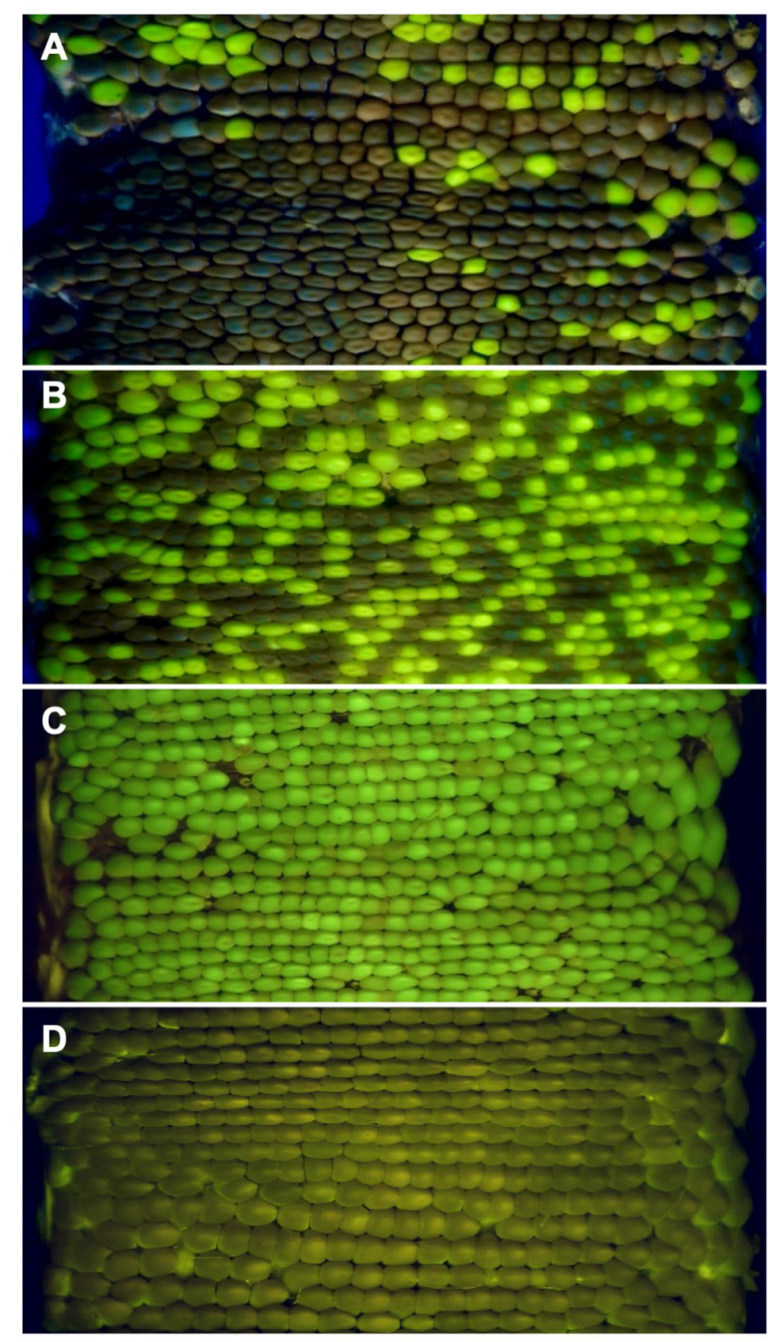

FIGURE 3 | Maize ear projections demonstrate a strong male-specific transmission defect associated with the GFP-expressing Zmlarp6c1::DsgR82C05 allele. (A) Zmlarp6c1::Ds/+ crossed as a male (52 GFP kernels $/ 420$ total kernels $=12.4 \%$ transmission). (B) The same Zmlarp6c1::Ds/+ plant crossed as a female (246 GFP kernels/479 total kernels $=51.4 \%$ transmission). (C) Representative ear resulting from a cross of a homozygous Zmlarp6c1::Ds plant as a male to a wild-type female (average seed set $=319$, standard deviation 101, $n=5$ ears).

(D) Representative ear resulting from a cross of a homozygous wild-type plant (a sibling from a closely related Zmlarp6c1::Ds family) as a male to a wild-type female (average seed set $=277$, standard deviation $50, n=5$ ears).

indirectly, given that seed production is limited to ovules successfully pollinated and fertilized. Analysis of all ears in the dataset individually showed a significant correlation between GFP transmission rate and the total number of seeds on an ear (Figure 5) $(p=0.0003)$. This is consistent with a strong effect of the level of competition with wild-type pollen on the ability of Zmlarp6c1::Ds pollen to successfully fertilize and generate a seed. These data argue that Zmlarp $6 c 1$ is a crucial contributor to pollen competitive ability in vivo, and suggest that its function is manifested post-pollination.
One possibility to explain the competitive defect would be slowed pollen tube germination, and/or a reduced growth rate for pollen tubes. To assess these possibilities, we characterized pollen tube germination and growth in vitro (Figure 6A). Pollen populations from homozygous mutant and wild-type fieldgrown plants was scored at 15 and $30 \mathrm{~min}$ after exposure to pollen growth medium (PGM), with germinated, ungerminated and ruptured pollen grains counted. (Ruptured pollen grains have ceased growing after releasing cytoplasm into the media, apparently due to loss of cell wall integrity at the growing pollen tube tip.) Altered germination dynamics were associated with loss of Zmlarp6c1 function (Figure 6B). Analysis of four replicates comparing wild-type and Zmlarp6c1::Ds pollen grown in vitro shows the expected significant effect of time on germination, with significant decrease in the percentage of ungerminated pollen from 15 to $30 \mathrm{~min}$ in both genotypes ( $p=1.02 \mathrm{E}-05)$, along with a concomitant increase in germinated and ruptured pollen. Genotype was also a significant predictor of germination response $(p=0.0047)$, confirming that Zmlarp6c1::Ds pollen is associated with a higher proportion of ungerminated pollen grains. Notably, although the proportion of ungerminated Zmlarp6c1::Ds pollen was higher than wild-type at both time points, by $30 \mathrm{~min}$ the proportional response in the mutant was similar to that of wild-type pollen at $15 \mathrm{~min}$ (Figure $\mathbf{6 B}$, and individual replicates in Supplementary Figure 3). These data are consistent with the Zmlarp6c1::Ds defect causing a delay in pollen tube germination, rather than an absolute inhibition of germination. Finally, pollen tube lengths were measured at the 30 min timepoint for both Zmlarp6c1::Ds-GFP mutant and wildtype populations. Consistent with the competitive defect detected in vivo, mutant pollen was associated with significantly shorter pollen tubes than wild-type, with an average 31.5\% tube length reduction associated with loss of Zmlarp $6 c 1$ function (Figure 6C and Supplementary Figure 4).

As an initial assessment as to whether the Zmlarp6c1::Ds-GFP mutant pollen was associated with defects prior to the progamic phase (i.e., aberrant pollen grain development, potentially leading to reduced competitiveness following pollination), we measured pollen grain diameter and determined nuclei number in pollen fixed upon anthesis. No significant differences were found in pollen grain diameters comparing sibling wild-type and Zmlarp6c1::Ds-GFP heterozygotes, nor did Dyecyle Green staining of DNA identify significant differences in the number of nuclei between these pollen populations (Supplementary Figure 5). Collectively, these findings suggest that the important role played by $Z m L A R P 6 c 1$ in male gametophyte function is primarily manifested in the post-pollination, progamic phase of gametophytic development, rather than in the development of the pollen grain itself.

\section{DISCUSSION}

Flowering plants have a complex sexual reproduction system, which includes the short but critical gametophytic generation, involving pollination followed by double fertilization, and triggering development of the progeny seed. Notably, 
TABLE 1 | Transmission of larp6c1::DsGFP in reciprocal outcrosses.

\begin{tabular}{|c|c|c|c|c|c|}
\hline larp6c1::DsGFP/+ plant/season & Direction of outcross to wild-type & \# GFP kernels & \# wt kernels & $\%$ GFP & $p$-value $\left(\chi^{2}\right)$ \\
\hline \multirow[t]{2}{*}{$1 / 2018$} & Male & 30 & 83 & 26.5 & $<10^{-6}$ \\
\hline & Female & 124 & 98 & 55.9 & 0.081 \\
\hline \multirow[t]{2}{*}{$2 / 2018$} & Male & 32 & 160 & 16.7 & $<10^{-6}$ \\
\hline & Female & 187 & 209 & 47.2 & 0.269 \\
\hline \multirow[t]{2}{*}{$3 / 2018$} & Male & 19 & 257 & 6.9 & $<10^{-6}$ \\
\hline & Female & 238 & 228 & 51.1 & 0.643 \\
\hline \multirow[t]{2}{*}{$4 / 2018$} & Male & 63 & 285 & 18.1 & $<10^{-6}$ \\
\hline & Female & 184 & 193 & 48.8 & 0.643 \\
\hline \multirow[t]{2}{*}{$1 / 2019$} & Male & 38 & 119 & 24.2 & $<10^{-6}$ \\
\hline & Female & 221 & 211 & 51.2 & 0.630 \\
\hline \multirow[t]{2}{*}{ 2/2019 } & Male & 12 & 439 & 2.7 & $<10^{-6}$ \\
\hline & Female & 224 & 171 & 56.7 & 0.008 \\
\hline \multirow[t]{2}{*}{ 3/2019 } & Male & 52 & 368 & 12.4 & $<10^{-6}$ \\
\hline & Female & 246 & 233 & 51.4 & 0.553 \\
\hline \multirow[t]{2}{*}{ 4/2019 } & Male & 9 & 256 & 3.4 & $<10^{-6}$ \\
\hline & Female & 221 & 210 & 51.3 & 0.596 \\
\hline \multirow[t]{2}{*}{$5 / 2019$} & Male & 1 & 187 & 0.5 & $<10^{-6}$ \\
\hline & Female & 148 & 154 & 49.0 & 0.730 \\
\hline
\end{tabular}

A

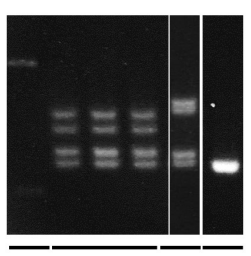

곳

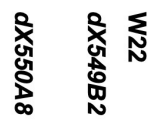

C

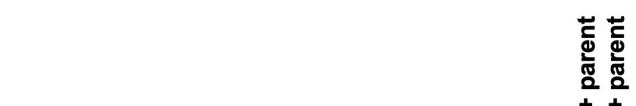

D

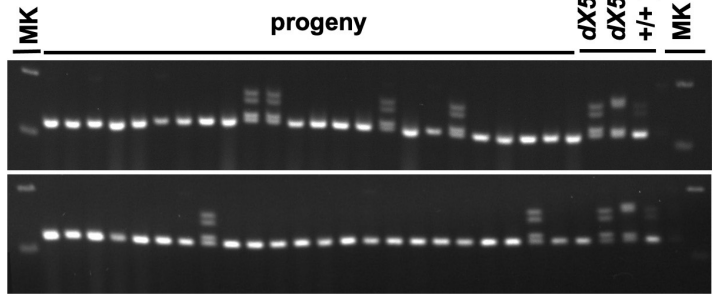

蒙 蒙

๕ั ฮ

去志范

产

progeny

장 중 $+\frac{1}{ \pm}$

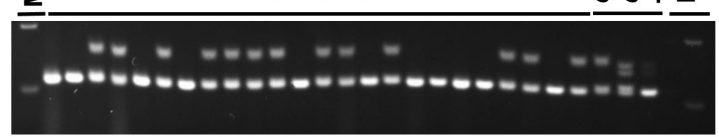

B

WT

GAGGACTCGTCTCGG

AACAGCCTCGAG

Zmlarp6c1::Ds-GFP GAGGACTCGTCTCGG-CGTCTCGGAACAGCCTCGAG 8 bp duplication

dX550A8

GAGGACTCGTCTCGC-CGTCTCGGAACAGCCTCGAG 8 bp footprint

dX549B2

\section{GAGGACTCGTCTCGG- - TCTCGGAACAGCCTCGAG 6 bp footprint}

FIGURE 4 | Ds excision alleles derived from Zmlarp6c1::DsgR82C05 validate that the male specific transmission defect is due to loss of ZmLARP6c1 function. (A) PCR genotyping using primers F2 and R2 (Figure 2) documents isolation of two derivative alleles (dX550A8 and dX549B2) due to excision of the Ds-GFP element from Zmlarp6c1::DsgR82C05. W22: comparator wild-type inbred; MK: DNA size marker. (B) Sequencing of the derivative alleles shows that $d X 550 A 8$ and dX549B2 are associated with an 8-bp and 6-bp footprints, respectively, in the Zmlarp6c1 coding sequence. (C) Zmlarp6c1-dX550A8 is associated with a male-specific transmission defect, with 6 out of 48 progeny from a heterozygous male outcross inheriting the footprint (12.5\%). (D) Zmlarp6c1- $d X 549 B 2$ segregates at a Mendelian ratio when transmitted through the male (13:11 from a heterozygous outcross). 
TABLE 2 | Transmission of larp6c1::DsGFP through the male when pollen load is varied.

\begin{tabular}{|c|c|c|c|c|c|}
\hline \multicolumn{2}{|c|}{$\begin{array}{l}\text { Experiment/ } \\
\text { Pollen load }\end{array}$} & \multirow{2}{*}{$\begin{array}{c}\text { \# GFP kernels } \\
30\end{array}$} & \multirow{2}{*}{$\begin{array}{c}\text { \# wt kernels } \\
83\end{array}$} & \multirow{2}{*}{$\begin{array}{c}\% \text { GFP } \\
26.5\end{array}$} & \multirow{2}{*}{$\frac{\boldsymbol{p} \text {-value }\left(\chi^{2}\right)}{0.010}$} \\
\hline 1 & HVY & & & & \\
\hline & SPS & 16 & 14 & 53.3 & (6.6151) \\
\hline \multirow[t]{2}{*}{2} & HVY & 32 & 160 & 16.7 & $\sim 0$ \\
\hline & SPS & 127 & 184 & 40.8 & (30.9695) \\
\hline \multirow[t]{2}{*}{3} & HVY & 19 & 257 & 6.9 & $\sim 0$ \\
\hline & SPS & 247 & 409 & 37.7 & (88.6719) \\
\hline \multirow[t]{2}{*}{4} & HVY & 63 & 285 & 18.1 & 0.976 \\
\hline & SPS & 135 & 599 & 18.4 & (0.0009) \\
\hline
\end{tabular}

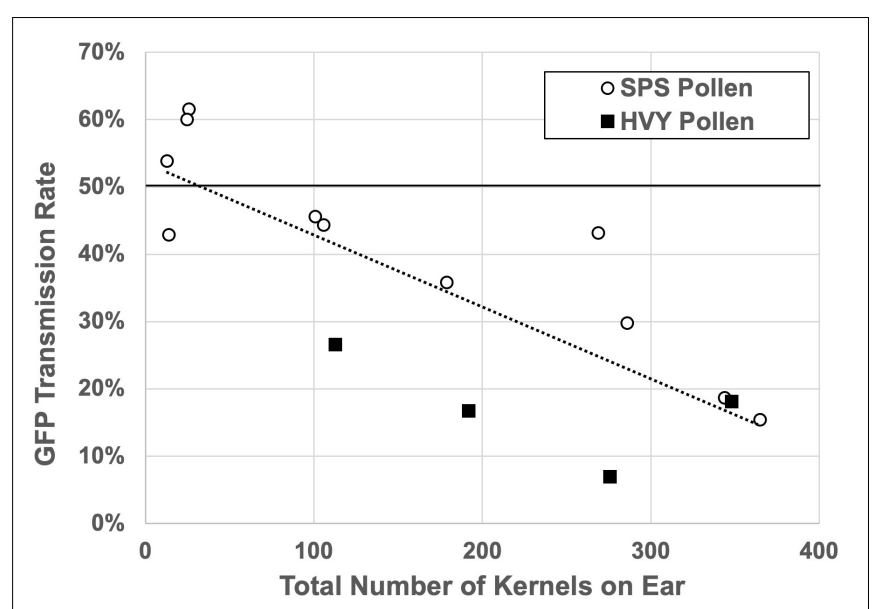

FIGURE 5 | Transmission of Zmlarp6c1::DsgR82C05 mutation is sensitive to pollen load. Outcomes of each separate ear with more than 10 kernels in the experiments from Table 2 are plotted. Pollination with heavy, near-saturating (HVY) pollen is associated with reduced transmission of Zmlarp6c1::Ds, relative to sparse (SPS) pollen ( $t$-test, $p=0.002601$ ). Moreover, linear regression (dotted line) indicates a significant correlation between total kernels per ear and transmission rate $\left(p=0.0003, R^{2}=0.647\right)$. Note that the two ears with $\sim 60 \%$ transmission are not significantly higher than $1: 1$, given the smaller populations they represent.

gametophytes express a significant subset of genes in plant genomes, which although reduced relative to the sporophyte (Honys and Twell, 2003; Chettoor et al., 2014; Rutley and Twell, 2015), enable developmental programs and environmental responses. Given that male gametophytic gene expression occurs after the genetic recombination of meiosis, and in organisms that are independent and have a free-living stage, there is considerable potential for expression of phenotypes, upon which evolutionary forces can act (Reese and Williams, 2019). In maize, with its prodigious production of large populations of pollen, lack of a biotic vector, and the extended stigma surface and transmitting tract of the female silk, there appears to be ample opportunity for gametophytic competition in the progamic phase of development (i.e., during pollen tube germination and growth). Assessing transmission rates can give an initial measure of the magnitude of a mutation's effect on gametophytic fitness (and presumably, biological function), and the same measure can also be used to determine whether competition itself influences fitness upon manipulation of pollen load (Arthur et al., 2003; Cole et al., 2005). The seed-expressed GFP phenotype linked to the Ds mutagenic element in the publicly available $D s$-GFP population (Li et al., 2013), not only facilitates the initial determination of mutant transmission rate (Warman et al., 2020), but also broadens the feasibility and precision of analytical approaches for assessing the influence of pollen competition on defects like that associated with Zmlarp6c1::Ds-GFP (Figure 5).

The biological processes that enable gametophytic function (and the genes that underlie them) are regulated developmentally, but the associated regulatory mechanisms remain unclear. Interestingly, evidence in multiple species indicates that a significant component enabling the transition from quiescent pollen grain to actively growing pollen tube is post-transcriptional control (Hafidh et al., 2016). In pollen of tobacco and Arabidopsis, cytoplasmic complexes are likely mechanistically important for storage of transcripts generated earlier in development, and eventual translation during pollen tube growth (Honys et al., 2009; Scarpin et al., 2017). Although such complexes have not been observed in maize pollen, the rapid germination response in vitro (pollen tube growth apparent in less than $15 \mathrm{~min}$ ) (Figure 6) is consistent with a transition that does not require de novo transcription. The detection of significant proteomic differences in germinated maize pollen at $30 \mathrm{~min}$ after exposed to media is also suggestive that control of translation plays a role in the regulation of pollen tube growth in maize (Walley et al., 2016). The protein homology, expression pattern and mutant phenotypes documented in this study raise the possibility that $Z m L a r p 6 c 1$ is a component of a translational control and/or RNA storage regulatory mechanism.

Few putative RNA-binding proteins have been characterized in detail in mature pollen in any species (Park et al., 2006), and until recently, none have been phenotypically associated with aberrant progamic development. However, a number of conserved sequence elements in transcript UTRs with potential or proven roles in influencing mRNA translation or stability have been identified (Hulzink et al., 2003), most notably in the tobacco ntp303 transcript (Hulzink et al., 2002). These are potential interaction sites for RNA-binding proteins, possibly including those of the LARP family (e.g., as observed for AtLARP1 and the TOP motif; Scarpin et al., 2020). As this report was in submission, a study of the Arabidopsis ortholog, AtLARP6C, provided data indicating that this protein is a bona fide RNA-binding protein, also specific to pollen grain and pollen tube, which targets transcripts with specific sequence motifs (the B-box) in the $5^{\prime}$ UTR (Billey et al., 2020). LARP6C binding, in a complex with the Poly-A Binding Protein (PABP), is proposed to regulate translation, decay and storage of its target transcripts. The data from Arabidopsis should facilitate the investigation of analogous putative RNA targets of ZmLARP6c1 in mature pollen and growing pollen tubes in maize.

The severe transmission defect for the Zmlarp6c1::Ds mutation indicates that the encoded protein is critical for wildtype pollen function in vivo. Moreover, the cellular phenotypes detected via assessment of Zmlarp $6 c 1:: D$ s pollen germination and growth in vitro indicate that the encoded protein plays a role in maize pollen post-germination, causing delayed germination 


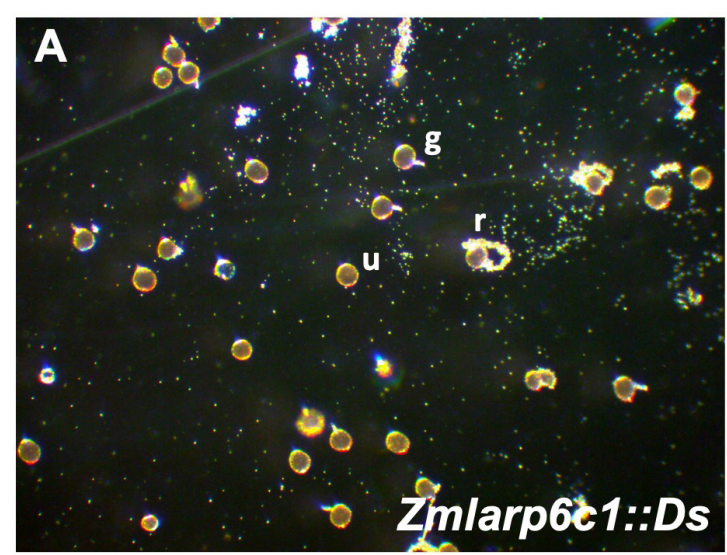

B

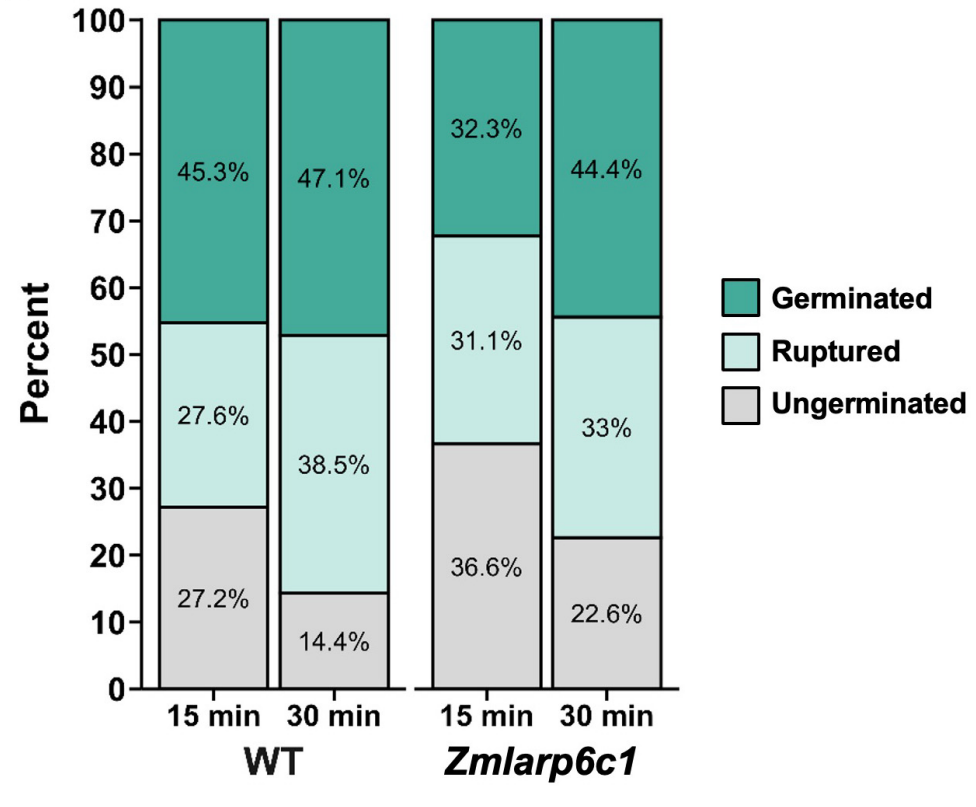

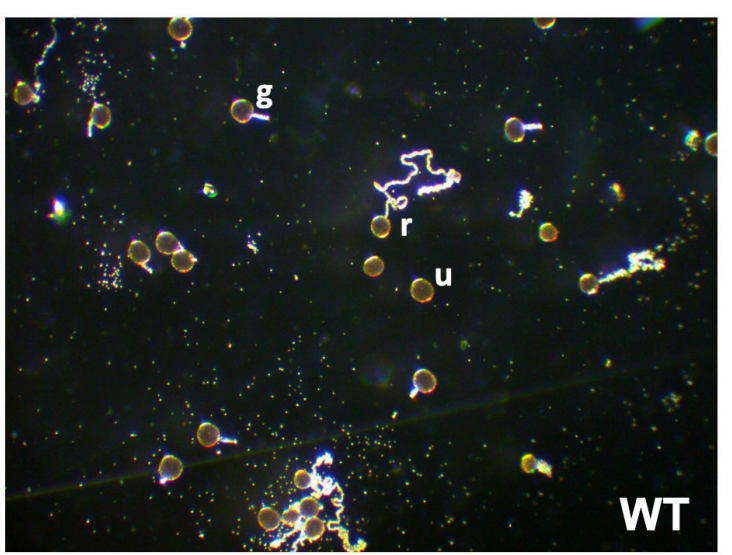

C

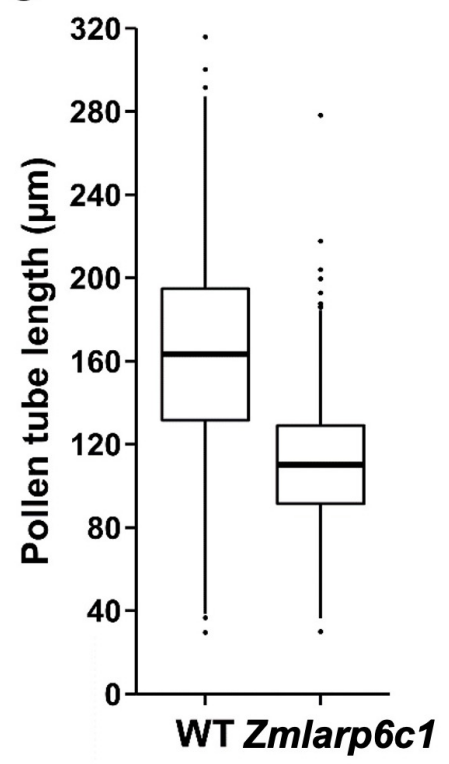

FIGURE 6 | In vitro, pollen from Zmlarp6c1::Ds plants is associated with shorter pollen tubes and altered germination dynamics. (A) Representative fields of pollen germinated in vitro, at 15 min post-exposure to liquid media. Pollen was collected from either a homozygous Zmlarp6c1::Ds plant, or a comparator wild-type (WT) plant. Fields were scored blindly (four biological replicates of three plants of each genotype, at least 125 pollen grains from each plant), categorizing pollen grains as germinated (g), ruptured (r), or ungerminated (u). (B) Combined data from four biological replicates, at 15 and 30 min after plating in PGM. Modeling the categorical response using a multinomial baseline-category logit model indicates genotype is a significant predictor $(p=0.0047)$, as is timepoint $(p=1.02 e-05)$. (C) Mutant pollen tube lengths at 30 min were significantly shorter than wild-type in all replications (Welch's $t$-test, all $p$-values $<10^{-15}$ ). Averaged across all four replicates, mutant pollen tubes were $31.5 \%$ shorter than wild-type sibling tubes.

dynamics and shorter pollen tubes when mutant. This is in contrast to the lack of a significant effect on two cellular parameters that indicative of effects earlier in development, pollen grain diameter and number of nuclei. Comparing across individual replicates, Zmlarp6c1::Ds pollen also appeared to show a higher variance in germination response, relative to the wildtype, raising the possibility that loss of Zmlarp $6 c 1$ function is associated with a more general loss of cellular robustness during pollen tube growth in vitro (Supplementary Figure 3). Notably, these phenotypes are distinct from those identified for mutants of the Arabidopsis AtLARP6C ortholog, which is primarily defective during a later stage of pollen tube growth, during guidance of the pollen tube to the embryo sac at the ovule (Billey et al., 2020). This raises the possibility of an evolutionary shift in the timing of LARP6C function in pollen in different plant lineages, with the protein acting earlier in maize relative to Arabidopsis. It will be important to investigate whether Zmlarp $6 c 1:: D s$ pollen tubes also display guidance defects, which we have not assessed.

Genetically encoded male sterility is of interest for plant breeding, crop production, and protection of patented varieties, for example, in the production of hybrid seeds. Currently, female lines with cytoplasmic male sterility ( $\mathrm{cms}$ ) or genic malesterility based on expression in the sporophyte (gms) are the preferred biological approaches for insuring only a single male 
parent during hybrid seed production, and obviate the need for mechanical detasseling (Wan et al., 2019). The observation that a single mutation such as Zmlarp6c1::Ds can cause a severe male-specific competitive, rather than absolute, defect raises the possibility of an alternative approach for controlling seed production via genic male sterility based on gametophytic expression (which we are designating "gms-g"). The conditional nature of the gametophytic Zmlarp $6 c 1:: D s$ defect - i.e., its ability to generate progeny is hindered only in the presence of wild-type pollen (Figure 3) - could be exploited to facilitate not only the generation of hybrid seed, but also seed for the parent female inbred line. This contrasts with sporophytic-based male-sterility of typical gms lines, in which production of any viable pollen is inhibited, complicating the large-scale production of these lines via self-pollination (Wan et al., 2019). In this scenario, a gms-g line that is homozygous for a competitiondefective male gametophyte can easily generate seed at scale via open self-pollination in plots isolated from wild-type pollen, eliminating competition. However, for hybrid seed production, the competitive male defect in the female gms-g parent would inhibit productive self-pollination in the presence of wild-type pollen from the hybrid partner male inbred. Similarly, such a genetically encoded competitive male gametophytic defect could be utilized for discouraging accidental transgene flow or loss of other patented alleles into non-target seed stock. It remains to be seen whether, in an open pollinated field that also provides a robust wild-type pollen source, a defective Zmlarp6c1 alone is a strong enough barrier to insure effective male sterility. The expression of the closely related Zmlarp $6 c 2$ at a low level in pollen (Figure 1) raises the possibility that this gene provides some remnant redundant function in the Zmlarp6c1::Ds-GFP line. Obtaining knockout mutations in this second gene would not only allow testing for genetic redundancy, but potentially also enhance gms-g effectiveness through a combination of both mutations.

\section{DATA AVAILABILITY STATEMENT}

The original contributions presented in the study are included in the article/Supplementary Materials, further inquiries can be directed to the corresponding author/s.

\section{AUTHOR CONTRIBUTIONS}

JF, CW, and LZ conceived and designed the experiments. LZ, ZV, and CW conducted the experiments and analyzed the data. LZ, $\mathrm{CW}$, and JF discussed and wrote the manuscript. All the authors edited, read and approved the manuscript.

\section{FUNDING}

This work was supported by the US Natural Science Foundation (IOS-1340050) and the National Natural Science Foundation of China (31601312).

\section{ACKNOWLEDGMENTS}

The authors thank the Dooner/Du collection for the Ds-GFP transposable element insertion mutant $t d s g R 82 C 05$. The authors would like to acknowledge statistical guidance from D. Jiang, OSU Statistics. Finally, thanks to S. Leiboff and other members of the OSU Botany \& Plant Pathology PF1 group for their helpful questions and comments.

\section{SUPPLEMENTARY MATERIAL}

The Supplementary Material for this article can be found online at: https://www.frontiersin.org/articles/10.3389/fpls.2021. 635244/full\#supplementary-material

\section{Supplementary Table 1 | Primers used in this study}

Supplementary Table 2 | Transmission of larp6c1::DsGFP in self crosses.

Supplementary Figure 1 |Zmlarp6c1 expression is enriched specifically in mature pollen. (A) Expression profiling data from the Walley et al. (2016) maize developmental atlas, for GRMZM2G323499/Zm00001d018613. RNA-seq data for all 23 different tissue types assessed (blue), with corresponding proteomic (orange), and phosphoproteomic (gray) profiling data for the same tissues. Two additional, relevant samples were assessed for proteomic data: B73 (inbred line) Germinated Pollen and W23 (inbred line) Mature Pollen. Although Zmlarp6c1 transcript is detected in mature leaf, the translated protein is only detected in pollen samples. FPKM, fragments per kilobase of exon model per million reads mapped; dNSAF, distributed normalized spectral abundance factor. (B) Focused transcriptome profiling of maize male gametophyte development (Warman et al., 2020) indicates that the Zmlarp6c1 transcript (Zm00001d018613_T004) is highest in mature pollen, but largely excluded from the sperm cells isolated from mature pollen. This suggests the transcript is specifically enriched in the pollen vegetative cell, which drives pollen tube germination and growth.

Supplementary Figure 2 | Alignments of WT, dX550A8 and dX549B2 amino acid sequences. Red shade, La motif; blue shade, RRM-L; black dot shade, altered residues in derivative alleles; orange oval, two amino acids added by the $d \times 549 B 2$ 6 bp footprint at the insertion site.

Supplementary Figure 3 |Zmlarp6c1::Ds-GFP and wild-type pollen germination, separated by replicate. Variance across each replicate is apparent. However, all show a trend toward a smaller percentage of ungerminated pollen grains at $30 \mathrm{~min}$ than at $15 \mathrm{~min}$, in both genotypes; and Zmlarp6c1 pollen associated with a higher fraction of ungerminated pollen than wild-type. Modeling the categorical response using a multinomial baseline-category logit model indicates Replicate 2 is a significant factor predictive of a high proportion of Ruptured grains ( $p=0.02059$ ), whereas Replicate 4 is a significant factor predictive of a low proportion of Ungerminated grains $(p=0.0134)$.

Supplementary Figure 4 | Pollen from homozygous Zmlarp6c1::Ds-GFP plants is associated with shorter pollen tubes. Pollen from homozygous Zmlarp6c1::Ds-GFP and comparator wild-type plants was germinated in pollen growth medium for $30 \mathrm{~min}$, imaged, and pollen tube lengths from four replicates were measured. Mutant pollen tubes were significantly shorter than wild-type in all replicates (Welch's $t$-test, all $p$-values $<10^{-15}$ ).

Supplementary Figure 5 | Pollen grain diameter and nuclei count showed no differences between wild-type and mutant pollen. (A) At least 150 pollen grains were measured per replicate. (B) DyeCycle green fluorescent dye was used to stain DNA in fixed pollen, and distinct nuclei visible in each grain were counted blindly. Although maize pollen grains are expected to have three nuclei at maturity (vegetative cell plus two sperm cells), not every nucleus is discernible in every grain, due to the large size of the pollen grain and presumed variation in staining efficiency. All data are means of four biological replicates with error bars indicating SD. 


\section{REFERENCES}

Adamczyk, B. J., and Fernandez, D. E. (2009). MIKC* MADS domain heterodimers are required for pollen maturation and tube growth in Arabidopsis. Plant Physiol. 149, 1713-1723. doi: 10.1104/pp.109.135806

Aoki, K., Adachi, S., Homoto, M., Kusano, H., Koike, K., and Natsume, T. (2013). LARP1 specifically recognizes the $3^{\prime}$ terminus of poly(A) mRNA. FEBS Lett. 587, 2173-2178. doi: 10.1016/j.febslet.2013.05.035

Arthur, K. M., Vejlupkova, Z., Meeley, R. B., and Fowler, J. E. (2003). Maize ROP2 GTPase provides a competitive advantage to the male gametophyte. Genetics 165, 2137-2151.

Bayfield, M. A., Yang, R., and Maraia, R. J. (2010). Conserved and divergent features of the structure and function of La and La-related proteins (LARPs). Biochim. Biophys. Acta 1799, 365-378. doi: 10.1016/j.bbagrm.2010.01.011

Billey, E., Hafidh, S., Cruz-Gallardo, I., Litholdo, C. G., Jean, V., Marie-Christine Carpentier, M. C., et al. (2020). LARP6C regulates selective mRNA translation to promote pollen tube guidance in Arabidopsis thaliana. bioRxiv [Preprint]. doi: 10.1101/2020.11.27.401307

Bousquet-Antonelli, C., and Deragon, J. M. (2009). A comprehensive analysis of the La-motif protein superfamily. RNA 15, 750-764. doi: 10.1261/rna.1478709

Cai, L., Fritz, D., Stefanovic, L., and Stefanovic, B. (2010). Binding of LARP6 to the conserved $5^{\prime}$ stem-loop regulates translation of mRNAs encoding type I collagen. J. Mol. Biol. 395, 309-326. doi: 10.1016/j.jmb.2009.11.020

Chang, F., Gu, Y., Ma, H., and Yang, Z. (2013). AtPRK2 promotes ROP1 activation via RopGEFs in the control of polarized pollen tube growth. Mol. Plant 6, 1187-1201. doi: 10.1093/mp/sss103

Chettoor, A. M., Givan, S. A., Cole, R. A., Coker, C. T., Unger-Wallace, E., Vejlupkova, Z., et al. (2014). Discovery of novel transcripts and gametophytic functions via RNA-seq analysis of maize gametophytic transcriptomes. Genome Biol. 15:414. doi: 10.1186/s13059-014-0414-2

Cheung, A. Y., Wang, H., and Wu, H. M. (1995). A floral transmitting tissuespecific glycoprotein attracts pollen tubes and stimulates their growth. Cell 82, 383-393. doi: 10.1016/0092-8674(95)90427-1

Cho, H., Cho, H. S., and Hwang, I. (2019). Emerging roles of RNA-binding proteins in plant development. Curr. Opin. Plant Biol. 51, 51-57. doi: 10.1016/j.pbi.2019. 03.016

Ciuzan, O., Hancock, J., Pamfil, D., Wilson, I., and Ladomery, M. (2015). The evolutionarily conserved multifunctional glycine-rich RNA-binding proteins play key roles in development and stress adaptation. Physiol. Plant 153, 1-11. doi: 10.1111/ppl.12286

Cole, R. A., Synek, L., Zarsky, V., and Fowler, J. E. (2005). SEC8, a subunit of the putative Arabidopsis exocyst complex, facilitates pollen germination and competitive pollen tube growth. Plant Physiol. 138, 2005-2018. doi: 10.1104/ pp.105.062273

Conrad, L. J., and Brutnell, T. P. (2005). Ac-immobilized, a stable source of Activator transposase that mediates sporophytic and gametophytic excision of Dissociation elements in maize. Genetics 171, 1999-2012. doi: 10.1534/genetics. 105.046623

Cui, Y., Rao, S., Chang, B., Wang, X., Zhang, K., Hou, X., et al. (2015). AtLal protein initiates IRES-dependent translation of WUSCHEL mRNA and regulates the stem cell homeostasis of Arabidopsis in response to environmental hazards. Plant Cell Environ. 38, 2098-2114. doi: 10.1111/pce.12535

Dedow, L. K., and Bailey-Serres, J. (2019). Searching for a match: structure, function and application of sequence-specific RNA-binding proteins. Plant Cell Physiol. 60, 1927-1938. doi: 10.1093/pcp/pcz072

Deragon, J. M. (2020). Distribution, organization an evolutionary history of La and LARPs in eukaryotes. RNA Biol. 19, 1-9. doi: 10.1080/15476286.2020.1739930

Dresselhaus, T., Sprunck, S., and Wessel, G. M. (2016). Fertilization mechanisms in flowering plants. Curr. Biol. 26, R125-R139. doi: 10.1016/j.cub.2015.12.032

Dreyfuss, G., Kim, V. N., and Kataoka, N. (2002). Messenger-RNA-binding proteins and the messages they carry. Nat. Rev. Mol. Cell Biol. 3, 195-205. doi: $10.1038 / \mathrm{nrm} 760$

Eichhorn, C. D., Chug, R., and Feigon, J. (2016). hLARP7 C-terminal domain contains an xRRM that binds the $3^{\prime}$ hairpin of 7SK RNA. Nucleic Acids Res. 44, 9977-9989. doi: 10.1093/nar/gkw833

Eichhorn, C. D., Yang, Y., Repeta, L., and Feigon, J. (2018). Structural basis for recognition of human 7SK long noncoding RNA by the La-related protein
Larp7. Proc. Natl. Acad. Sci. U.S.A. 115, E6457-E6466. doi: 10.1073/pnas. 1806276115

Fedoroff, N. V. (2002). RNA-binding proteins in plants: the tip of an iceberg? Curr. Opin. Plant Biol. 5, 452-459. doi: 10.1016/s1369-5266(02)00280-7

Fleurdepine, S., Deragon, J. M., Devic, M., Guilleminot, J., and Bousquet-Antonelli, C. (2007). A bona fide La protein is required for embryogenesis in Arabidopsis thaliana. Nucleic Acids Res. 35, 3306-3321. doi: 10.1093/nar/gkm200

Hafidh, S., Fila, J., and Honys, D. (2016). Male gametophyte development and function in angiosperms: a general concept. Plant Reprod. 29, 31-51. doi: 10. 1007/s00497-015-0272-4

Honys, D., Rĕnák, D., Feciková, J., Jedelský, P. L., Nebesárová, J., Dobrev, P., et al. (2009). Cytoskeleton-associated large RNP complexes in tobacco male gametophyte (EPPs) are associated with ribosomes and are involved in protein synthesis, processing, and localization. J Proteome Res. 8, 2015-2031. doi: 10. $1021 /$ pr8009897

Honys, D., and Twell, D. (2003). Comparative analysis of the Arabidopsis pollen transcriptome. Plant Physiol. 132, 640-652. doi: 10.1104/pp.103.020925

Honys, D., and Twell, D. (2004). Transcriptome analysis of haploid male gametophyte development in Arabidopsis. Genome Biol. 5:R85. doi: 10.1186/gb2004-5-11-r85

Huang, J. T., Wang, Q., Park, W., Feng, Y., Kumar, D., Meeley, R., et al. (2017). Competitive ability of maize pollen grains requires paralogous serine threonine protein kinases STK1 and STK2. Genetics 207, 1361-1370. doi: 10.1534/genetics. 117.300358

Hulskamp, M., Schneitz, K., and Pruitt, R. E. (1995). Genetic evidence for a longrange activity that directs pollen tube guidance in Arabidopsis. Plant Cell 7, 57-64. doi: 10.1105/tpc.7.1.57

Hulzink, R. J., de Groot, P. F., Croes, A. F., Quaedvlieg, W., Twell, D., Wullems, G. J., et al. (2002). The $5^{\prime}$-untranslated region of the ntp303 gene strongly enhances translation during pollen tube growth, but not during pollen maturation. Plant Physiol. 129, 342-353. doi: 10.1104/pp.001701

Hulzink, R. J., Weerdesteyn, H., Croes, A. F., Gerats, T., van Herpen, M. M., and van Helden, J. (2003). In silico identification of putative regulatory sequence elements in the $5^{\prime}$-untranslated region of genes that are expressed during male gametogenesis. Plant Physiol. 132, 75-83. doi: 10.1104/pp.102.014894

Johnson, M. A., Harper, J. F., and Palanivelu, R. (2019). A fruitful journey: pollen tube navigation from germination to fertilization. Annu. Rev. Plant Biol. 70, 809-837. doi: 10.1146/annurev-arplant-050718-100133

Kaya, H., Nakajima, R., Iwano, M., Kanaoka, M. M., Kimura, S., Takeda, S., et al. (2014). Ca2+-activated reactive oxygen species production by Arabidopsis RbohH and RbohJ is essential for proper pollen tube tip growth. Plant Cell 26, 1069-1080. doi: 10.1105/tpc.113.120642

Kim, Y. J., Zhang, D., and Jung, K. H. (2019). Molecular basis of pollen germination in cereals. Trends Plant Sci. 24, 1126-1136. doi: 10.1016/j.tplants.2019.08.005

Koster, T., Marondedze, C., Meyer, K., and Staiger, D. (2017). RNA-binding proteins revisited - the emerging Arabidopsis mRNA interactome. Trends Plant Sci. 22, 512-526. doi: 10.1016/j.tplants.2017.03.009

Kramer, M. C., Anderson, S. J., and Gregory, B. D. (2018). The nucleotides they are a-changin': function of RNA binding proteins in post-transcriptional messenger RNA editing and modification in Arabidopsis. Curr. Opin. Plant Biol. 45(Pt A), 88-95. doi: 10.1016/j.pbi.2018.05.010

Krueger, B. J., Jeronimo, C., Roy, B. B., Bouchard, A., Barrandon, C., Byers, S. A., et al. (2008). LARP7 is a stable component of the 7SK snRNP while P-TEFb, HEXIM1 and hnRNP A1 are reversibly associated. Nucleic Acids Res. 36, 2219-2229. doi: 10.1093/nar/gkn061

Lago, C., Clerici, E., Dreni, L., Horlow, C., Caporali, E., Colombo, L., et al. (2005). The Arabidopsis TFIID factor AtTAF6 controls pollen tube growth. Dev. Biol. 285, 91-100. doi: 10.1016/j.ydbio.2005.06.006

Lahr, R. M., Mack, S. M., Héroux, A., Blagden, S. P., Bousquet-Antonelli, C., Deragon, J. M., et al. (2015). The La-related protein 1-specific domain repurposes HEAT-like repeats to directly bind a 5'TOP sequence. Nucleic Acids Res. 43, 8077-8088. doi: 10.1093/nar/gkv748

Lalanne, E., and Twell, D. (2002). Genetic control of male germ unit organization in Arabidopsis. Plant Physiol. 129, 865-875. doi: 10.1104/pp.003301

Li, Y., Segal, G., Wang, Q., and Dooner, H. K. (2013). Gene tagging with engineered Ds elements in maize. Methods Mol. Biol. 1057, 83-99. doi: 10.1007/978-162703-568-2_6 
Lopes, A. L., Moreira, D., Ferreira, M. J., Pereira, A. M., and Coimbra, S. (2019). Insights into secrets along the pollen tube pathway in need to be discovered. J. Exp. Bot. 70, 2979-2992. doi: 10.1093/jxb/erz087

Maraia, R. J., Mattijssen, S., Cruz-Gallardo, I., and Conte, M. R. (2017). The La and related RNA-binding proteins (LARPs): structures, functions, and evolving perspectives. Wiley Interdiscip. Rev. RNA 8:e1430. doi: 10.1002/wrna.1430

Martino, L., Pennell, S., Kelly, G., Busi, B., Brown, P., Atkinson, R. A., et al. (2015). Synergic interplay of the La motif, RRM1 and the interdomain linker of LARP6 in the recognition of collagen mRNA expands the RNA binding repertoire of the La module. Nucleic Acids Res. 43, 645-660. doi: 10.1093/nar/gku1287

Mennie, A. K., Moser, B. A., and Nakamura, T. M. (2018). LARP7-like protein Pof8 regulates telomerase assembly and poly(A)+TERRA expression in fission yeast. Nat. Commun. 9:586. doi: 10.1038/s41467-018-02874-0

Merret, R., Descombin, J., Juan, Y. T., Favory, J. J., Carpentier, M. C., Chaparro, C., et al. (2013a). XRN4 and LARP1 are required for a heat-triggered mRNA decay pathway involved in plant acclimation and survival during thermal stress. Cell Rep. 5, 1279-1293. doi: 10.1016/j.celrep.2013.11.019

Merret, R., Martino, L., Bousquet-Antonelli, C., Fneich, S., Descombin, J., Billey, E., et al. (2013b). The association of a La module with the PABP-interacting motif PAM2 is a recurrent evolutionary process that led to the neofunctionalization of La-related proteins. RNA 19, 36-50. doi: 10.1261/rna.035469.112

Park, J. I., Endo, M., Kazama, T., Saito, H., Hakozaki, H., Takada, Y., et al. (2006). Molecular characterization of two anther-specific genes encoding putative RNA-binding proteins. AtRBP45s, in Arabidopsis thaliana. Genes Genet. Syst. 81, 355-359. doi: 10.1266/ggs.81.355

Pina, C., Pinto, F., Feijo, J. A., and Becker, J. D. (2005). Gene family analysis of the Arabidopsis pollen transcriptome reveals biological implications for cell growth, division control, and gene expression regulation. Plant Physiol. 138, 744-756. doi: $10.1104 /$ pp.104.057935

Prall, W., Sharma, B., and Gregory, B. D. (2019). Transcription is just the beginning of gene expression regulation: the functional significance of RNA-binding proteins to post-transcriptional processes in plants. Plant Cell Physiol. 60, 1939-1952. doi: 10.1093/pcp/pcz067

Procissi, A., de Laissardière, S., Férault, M., Vezon, D., Pelletier, G., and Bonhomme, S. (2001). Five gametophytic mutations affecting pollen development and pollen tube growth in Arabidopsis thaliana. Genetics 158, 1773-1783.

Reese, J. B., and Williams, J. H. (2019). How does genome size affect the evolution of pollen tube growth rate, a haploid performance trait? Am. J. Bot. 106, 1011-1020. doi: 10.1002/ajb2.1326

Reňák, D., Dupl'áková, N., and Honys, D. (2012). Wide-scale screening of T-DNA lines for transcription factor genes affecting male gametophyte development in Arabidopsis. Sex Plant Reprod. 25, 39-60. doi: 10.1007/s00497-011-0178-8

Rutley, N., and Twell, D. (2015). A decade of pollen transcriptomics. Plant Reprod. 28, 73-89. doi: 10.1007/s00497-015-0261-7

Scarpin, M. R., Leiboff, S., and Brunkard, J. O. (2020). Parallel global profiling of plant TOR dynamics reveals a conserved role for LARP1 in translation. eLife 9:e58795. doi: 10.7554/eLife.58795
Scarpin, M. R., Sigaut, L., Temprana, S. G., Boccaccio, G. L., Pietrasanta, L. I., and Muschietti, J. P. (2017). Two Arabidopsis late pollen transcripts are detected in cytoplasmic granules. Plant Direct. 1:e00012. doi: 10.1002/pld3.12

Schindelin, J., Arganda-Carreras, I., Frise, E., Kaynig, V., Longair, M., Pietzsch, T., et al. (2012). Fiji: an open-source platform for biological-image analysis. Nat. Methods 9, 676-682. doi: 10.1038/nmeth.2019

Schreiber, D. N., and Dresselhaus, T. (2003). In vitro pollen germination and transient transformation ofZea mays and other plant species. Plant Mol. Biol.Rep. 21, 31-41. doi: 10.1007/BF02773394

Tamura, K., Stecher, G., Peterson, D., Filipski, A., and Kumar, S. (2013). MEGA6: molecular evolutionary genetics analysis version 6.0. Mol. Biol. Evol. 30, 27252729. doi: 10.1093/molbev/mst197

Tattersall, E. A. R., Ergul, A., AlKayal, F., DeLuc, L., Cushman, J. C., and Cramer, G. R. (2005). Comparison of methods for isolating high-quality RNA from leaves of grapevine. Am. J. Enol. Vit. 56, 400-406.

Walbot, V., and Evans, M. M. (2003). Unique features of the plant life cycle and their consequences. Nat. Rev. Genet. 4, 369-379. doi: 10.1038/nrg1064

Walley, J. W., Sartor, R. C., Shen, Z., Schmitz, R. J., Wu, K. J., Urich, M. A., et al. (2016). Integration of omic networks in a developmental atlas of maize. Science 353, 814-818. doi: 10.1126/science.aag1125

Wan, X., Wu, S., Li, Z., Dong, Z., An, X., Ma, B., et al. (2019). Maize genic male-sterility genes and their applications in hybrid breeding: progress and perspectives. Mol. Plant 12, 321-342. doi: 10.1016/j.molp.2019.01.014

Warman, C., Panda, K., Vejlupkova, Z., Hokin, S., Unger-Wallace, E., Cole, R. A., et al. (2020). High expression in maize pollen correlates with genetic contributions to pollen fitness as well as with coordinated transcription from neighboring transposable elements. PLoS Genet. 16:e1008462. doi: 10.1371/ journal.pgen.1008462

Warman, C., Sullivan, C. M., Preece, J., Buchanan, M. E., Vejlupkova, Z., Jaiswal, P., et al. (2021). A cost-effective maize ear phenotyping platform enables rapid categorization and quantification of kernels. Plant J. doi: 10.1111/tpj.15166

Wolin, S. L., and Cedervall, T. (2002). The La protein. Annu. Rev. Biochem. 71, 375-403.

Zhang, B., Jia, J., Yang, M., Yan, C., and Han, Y. (2012). Overexpression of a LAM domain containing RNA-binding protein LARP1c induces precocious leaf senescence in Arabidopsis. Mol. Cells 34, 367-374. doi: 10.1007/s10059-0120111-5

Conflict of Interest: The authors declare that the research was conducted in the absence of any commercial or financial relationships that could be construed as a potential conflict of interest.

Copyright (C) 2021 Zhou, Vejlupkova, Warman and Fowler. This is an open-access article distributed under the terms of the Creative Commons Attribution License (CC BY). The use, distribution or reproduction in other forums is permitted, provided the original author(s) and the copyright owner(s) are credited and that the original publication in this journal is cited, in accordance with accepted academic practice. No use, distribution or reproduction is permitted which does not comply with these terms. 